\title{
On the relationship between Atlantic Niño variability and ocean dynamics
}

\author{
Tina Dippe ${ }^{1} \mathbb{D} \cdot$ Richard J. Greatbatch $^{1,2} \cdot$ Hui Ding ${ }^{3}$
}

Received: 21 December 2016 / Accepted: 30 September 2017 / Published online: 28 October 2017

(c) The Author(s) 2017. This article is an open access publication

\begin{abstract}
The Atlantic Niño is the dominant mode of interannual sea surface temperature (SST) variability in the eastern equatorial Atlantic. Current coupled global climate models struggle to reproduce its variability. This is thought to be partly related to an equatorial SST bias that inhibits summer cold tongue growth. Here, we address the question whether the equatorial SST bias affects the ability of a coupled global climate model to produce realistic dynamical SST variability. We assess this by decomposing SST variability into dynamical and stochastic components. To compare our model results with observations, we employ empirical linear models of dynamical SST that, based on the Bjerknes feedback, use the two predictors sea surface height and zonal surface wind. We find that observed dynamical SST variance shows a pronounced seasonal cycle. It peaks during the active phase of the Atlantic Niño and is then roughly 4-7 times larger than stochastic SST variance. This indicates that the Atlantic Niño is a dynamical phenomenon that is related to the Bjerknes feedback. In the coupled model, the SST bias suppresses the summer peak in dynamical SST variance. Bias reduction, however, improves the representation of the seasonal cold tongue and enhances dynamical SST variability by supplying a background state that allows key feedbacks of the tropical ocean-atmosphere system to
\end{abstract}

Tina Dippe

tdippe@geomar.de

1 GEOMAR Helmholtz Centre for Ocean Research Kiel, Kiel, Germany

2 Faculty of Mathematics and Natural Sciences, Christian Albrechts University, Kiel, Germany

3 Cooperate Institute for Research in Environmental Sciences, University of Colorado and NOAA Earth Systems Research Laboratory, Boulder, USA operate in the model. Due to the small zonal extent of the equatorial Atlantic, the observed Bjerknes feedback acts quasi-instantaneously during the dynamically active periods of boreal summer and early boreal winter. Then, all elements of the observed Bjerknes feedback operate simultaneously. The model cannot reproduce this, although it hints at a better performance when using bias reduction.

\section{Introduction}

The Atlantic Niño is the dominant mode of interannual variability in equatorial Atlantic sea surface temperature (SST). It modulates the seasonal development of the equatorial Atlantic cold tongue and peaks during May-August (Xie and Carton 2004). Similar to other modes of equatorial SST variability, it is the source of a number of teleconnections (e.g. Janicot et al. 1998; Mohino and Losada 2015), both regionally and globally. Through its close relationship with the Inter-Tropical Convergence Zone, it especially affects rainfall variability over the surrounding continents, exerting an important socio-economic impact (Hirst and Hastenrath 1983).

Efforts to simulate and predict equatorial Atlantic seasonal-to-interannual SST variability with state-of-the-art coupled global climate models (CGCMs) have not been very successful (Stockdale et al. 2006; Kushnir et al. 2006; Hu and Huang 2007). One reason for this is that most CGCMs suffer from a strong coupled bias in the tropical eastern Atlantic (e.g. Richter and Xie 2008; Grodsky et al. 2012; Wang et al. 2014). The SST signature of this bias stretches from the coast of Namibia and Angola into the equatorial Atlantic and is well established in the cold tongue region in the annual mean. Chang et al. (2007) and Richter et al. (2012) show that the equatorial SST bias is associated with 
a fundamentally biased mean state in this region. The pool of warm surface waters that is observed in the western ocean basin shifts into the central ocean basin in biased simulations. The thermocline in the cold tongue region deepens, and upwelling is strongly reduced. The Atlantic cold tongue-the dominant feature of the SST seasonal cycle in the tropical Atlantic-cannot be established. Without a realistic cold tongue, however, CGCMs struggle to capture the observed Atlantic Niño, even in the presence of realistic forcing. Another factor that likely contributes to the models' problems is that the dynamical nature of the Atlantic Niño is not yet fully understood.

While the name Atlantic "Niño" suggests a phenomenon that is essentially an Atlantic version of the Pacific El Niño-Southern Oscillation (ENSO), a number of differences exist between the two phenomena (e.g. Keenlyside and Latif 2007; Burls et al. 2011; Lübbecke and McPhaden 2012; Richter et al. 2013). Obvious are the differences in timing characteristics: Both positive and negative ENSO events generally peak in boreal winter and last for several months and in some cases even longer than a year. Atlantic Niño events on the other hand are phase-locked to boreal summer and rarely outlast a season. They have a smaller amplitude than their Pacific counterparts and appear to be the result of weaker atmosphere-ocean coupling. Additionally, while the canonical ENSO agrees with a self-sustained mode in the tropical Pacific, the Atlantic Niño requires external excitation (Zhu et al. 2012).

The dominant process that couples equatorial atmospheric and oceanic variability is the Bjerknes feedback (Bjerknes 1969). In a positive feedback, it relates SST and thermocline variability in the eastern ocean basin to zonal surface wind variability in the western ocean basin (u10) and lends growth to the Pacific (Bjerknes 1969) and Atlantic Niños (e.g. Keenlyside and Latif 2007; Burls et al. 2012; Lübbecke and McPhaden 2013; Deppenmeier et al. 2016). Traditionally, three elements of the Bjerknes feedback are considered when assessing the overall strength of the feedback: (1) Eastern ocean basin SST anomalies force u10 anomalies in the western ocean basin, (2) u10 anomalies trigger a thermocline response across the basin that can be measured via thermocline variability in the eastern ocean basin, and (3) eastern basin thermocline anomalies amplify the initial SST anomaly. A closed Bjerknes feedback loop is present when all three elements of the Bjerknes feedback are active simultaneously.

Note, however, that the simplified Bjerknes feedback outlined above is not the only process that acts in the equatorial oceans. Specifically, the "forcing direction" in the feedback elements (1)-(3) is not strict. In the closely coupled system of the equatorial oceans, wind variability in the western ocean basin for example can feed back directly to SST variability via the zonal advection feedback (e.g. Dijkstra
2006). Nevertheless, for the purpose of this study we will rely mainly on the dynamical framework of the simplified Bjerknes feedback.

An important aspect of the Bjerknes feedback is that it must not necessarily act instantaneously. This means that the individual elements of the Bjerknes feedback may be delayed (note that this delay within the positive Bjerknes feedback is not identical with the range of delayed negative feedbacks discussed in Neelin et al. (1998) that ultimately stop anomaly growth in the eastern ocean basin during an El Niño or La Niña event). Physically, the delay within the elements of the positive Bjerknes feedback is due to the fact that information about anomalies on one side of the ocean basin need to be transmitted across the basin to be able to affect the other side. In the atmosphere, this is done via relatively quick atmospheric adjustment to eastern ocean basin SST anomalies, which in turn produce anomalous zonal pressure gradients and result in western ocean basin zonal wind anomalies. In the ocean, zonal wind stress anomalies are translated into equatorial Kelvin waves (e.g. Dijkstra 2006). These Kelvin waves than travel westward across the ocean basin and feed the information about the wind variability in the west to the eastern ocean basin. Depending on the width of the ocean basin, the Kelvin wave transmission can happen on a time scale on the order of months. In the tropical Atlantic, Keenlyside and Latif (2007) and Richter et al. (2013), among others, have shown that wind variability in the western ocean basin precedes SST variability in the eastern ocean basin by about 1 month in boreal spring. In the tropical Pacific, this delay is longer due to the larger basin size.

Returning to the dynamical nature of the Atlantic Niño in comparison to ENSO events, Burls et al. (2011) show that the Atlantic and Pacific Niños rely on the Bjerknes feedback in subtly different ways. The Pacific Niño generally is the result of a free mode of interannual variability that is driven by the Bjerknes feedback; interactions with the seasonal cycle occur, but do not dominate ENSO SST variability. In the tropical Atlantic, on the other hand, the Bjerknes feedback is seasonally active (Richter 2016). It helps to develop the cold tongue and is involved in establishing the seasonal cycle. Burls et al. (2012) argue that the Atlantic Niño hence reflects a modulation of the seasonally active Bjerknes feedback instead of an independent mode of interannual variability.

Lastly, and in contrast to numerous studies that have provided evidence for a relationship between Atlantic Niño variability and the Atlantic Bjerknes feedback, Nnamchi et al. $(2015,2016)$ have proposed that the Atlantic Niño is essentially driven by stochastic processes in the atmosphere rather than by dynamical ocean processes that are potentially predictable. Likewise, Richter et al. (2014b) present 
Fig. 1 Annual mean SST bias relative to ERA-Interim SST in the a STD and b FLX assimilation runs in the tropical Atlantic. Positive values indicate that the model climatology is too warm. Solid (dashed) boxes show the Atl3 (WAtl) region

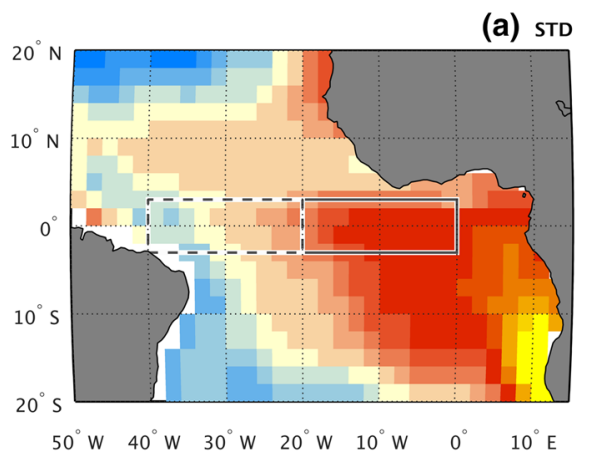

(b) FLX

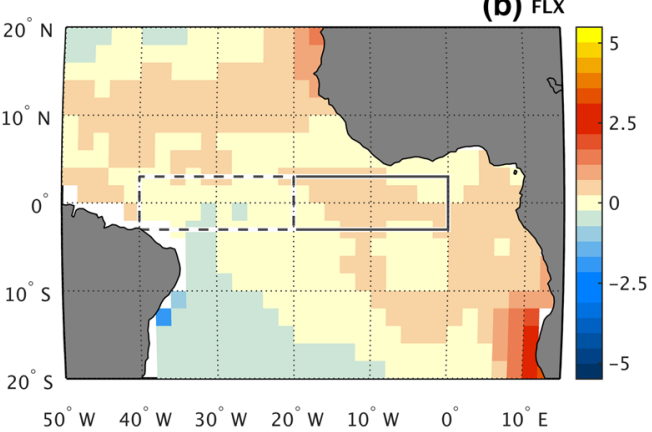

evidence for a significant stochastic component of Niño-like variability in the tropical Atlantic.

Here, we address two questions. First, do dynamical processes contribute to SST variability in the tropical Atlantic? Is there a seasonality to the ratio of dynamical and stochastic contributions? And second, does the presence of the SST bias - and hence the flawed mean state and missing summer cold tongue-affect the models' ability to accurately reproduce the observed dynamical SST variance? To answer these questions, we use two assimilation runs of the Kiel Climate Model (KCM) as well as reanalysis data and decompose SST variance into a part that is due to dynamical processes in the ocean and a stochastic part that is driven by noise.

The rest of the paper is structured as follows: Sect. 2 sketches the Kiel Climate Model and the method that we used to produce our assimilation runs, Sect. 3 reviews the assimilation runs with respect to the impact of the equatorial Atlantic SST bias. Section 4 presents our SST variance decomposition method; results for our assimilation runs and observations are compared in Sect. 5. Section 6 discusses the impact of lagged feedbacks on our results. A summary and discussion of the results is provided in Sect. 7.

\section{Model and methods}

To compare our results with the evolution of the observed climate system, we use the ERA-Interim (Dee 2011) and the Archiving, Validation, and Interpretation of Satellite Oceanographic (AVISO) datasets. We find that differences between ERA-Interim SST and other SST datasets are negligibly small. (Analysis results for alternative validation datasets such as the HadISST dataset (Rayner et al. 2003) are not shown. They differ from the analysis with respect to ERA-Interim only in details.) Furthermore, our variance decomposition approach requires additional surface zonal wind (u10) and sea surface height (SSH) data. We use u10 provided by ERA-Interim for the period 1981-2012, and the AVISO monthly mean SSH anomaly dataset for the period 1993-2012. Throughout this study, we refer to ERA-Interim
(AVISO) when we discuss an "observed" feature of SST and u10 (SSH).

Figure 1 shows important regions for our study as boxes. Atl3 spans the region $3^{\circ} \mathrm{S}-3^{\circ} \mathrm{N}, 20^{\circ} \mathrm{W}-0^{\circ} \mathrm{E}$ and is the Atlantic counterpart to the Pacific Nino3.4-region. It is the part of the equatorial Atlantic in which ocean-atmosphere coupling is most vigorous and that is hence used to assess SST variability associated with the Atlantic Niño. It is also the region in which the cold tongue is most pronounced in boreal summer. To the west of Atl3 is the western Atlantic region WAtl $\left(3^{\circ} \mathrm{S}-3^{\circ} \mathrm{N}, 40-20^{\circ} \mathrm{W}\right)$. In terms of the Bjerknes feedback, WAtl is crucial for the wind stress contributions to the feedback.

Model runs were performed with the Kiel Climate Model (KCM, Park et al. 2009), a coupled global climate model (CGCM). We used a low-resolution version of the KCM. The atmospheric component ECHAM5 (Roeckner et al. 2003 ) is run with 19 vertical levels in T31 horizontal resolution. The ocean component of the NEMO model (Océan Parallelisé Version 9, OPA9 Madec et al. 1998; Madec 2008) is run in the ORCA2-setup. ORCA2 has 31 vertical levels and an average horizontal resolution of $1.3^{\circ}$. Towards the equator, the horizontal resolution is refined to $0.5^{\circ}$. The model uses seasonally varying radiative forcing that corresponds to mid-twentieth century conditions. In particular, changes in greenhouse gas concentrations and aerosol loading are not considered.

We conducted two sets of experiments. The first set uses a standard version of the KCM ("STD"). The STD-SST climatology contains the SST bias in the southern subtropical Atlantic (Fig. 1), which is qualitatively comparable to the bias in other CGCMs (shown for example by Davey 2002; Richter and Xie 2008). The second experiment employs additional surface heat flux correction ("FLX", see below for details) to reduce the SST bias. We run three and eight ensemble members for the STD and FLX experiments runs, respectively. All ensemble members use the same wind stress forcing (see below), but differ in their initial conditions, which are taken from a control run at a time when the model is close to equilibrium. 
The STD and FLX experiments were run in partially coupled mode. Partial coupling is an assimilation technique that seeks to minimize the equatorial initialization shock in fully coupled hindcasts when they are started from partially coupled initial conditions (e.g. Ding et al. 2013; Thoma et al. 2015). In a partially coupled model the ocean and sea ice components are forced with observed wind stress anomalies that are added to the model's monthly mean wind stress climatology. All other aspects of the model are identical to the fully coupled model. In particular, thermal coupling between the ocean and the atmosphere is preserved, and SST and the atmospheric wind field remain fully prognostic variables.

Surface heat flux correction is employed in the FLX experiment to reduce the SST bias of the KCM. To diagnose the heat flux correction, we use the same methodology as Ding et al. (2015): During a control integration, we nudge the first ocean level of the model towards the monthly climatology of observed SST with a restoring time scale of 10 days. After 470 years, when the model has reached an equilibrium state, we continue our integration for another 70 years to diagnose the monthly climatological heat flux term that is associated with the SST restoring. This climatology of the "heat flux correction" is then added as a non-flowinteractive correction to the SST tendency while integrating the heat-flux corrected version of the KCM. For an overview of the performance of the two experiments in the equatorial Atlantic and the impact of the bias on the coupled system, refer to Sect. 3. Here, we note that Ding et al. (2015) showed a substantial improvement in the ability of the partially coupled model runs to reproduce observed SST variability in boreal summer in FLX compared to STD.

Monthly anomalies for the model integrations and validation datasets are calculated by detrending the data via leastsquares fitting, applied to each month separately. Note that we did not subtract the seasonal cycle from the monthly data prior to the detrending, since it did not yield qualitatively different results. We chose this method to not only calculate our anomalies relative to a static seasonal cycle but allow the possibility that the seasonal cycle itself may vary (linearly) on long time scales. The analysis period is 1981-2012 (1993-2012) for ERA-Interim and the KCM experiments (AVISO). For the KCM experiments, we detrend each ensemble member separately. The ensemble mean monthly anomaly is the average of the monthly anomalies of all ensemble members.

\section{Impact of the coupled bias on the equatorial Atlantic}

In this section, we assess SST and zonal wind biases in the tropical Atlantic for our KCM experiments. Because all ensemble members for both the STD and FLX assimilation

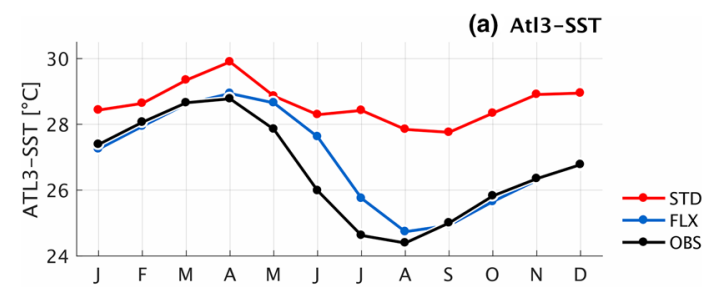

(b) Monthly SST-bias in Atl3

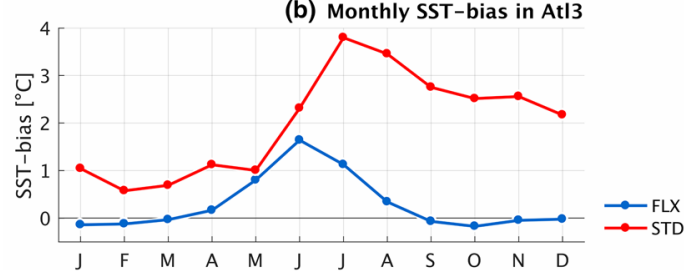

Fig. 2 a Seasonal cycle of SST in Atl3 for (black) ERA-Interim, (red) STD, and (blue) FLX for 1981-2012. b Monthly mean bias of Atl3 SST for (red) STD and (blue) FLX

experiments share their forcing of observed wind stress anomalies, the only difference between the ensemble means must be due to the bias correction in FLX. Hence, our analyses illustrate the impact that the bias has on the coupled equatorial system.

First, we assess the SST bias in STD and FLX. In the annual mean, the STD experiment shows the familiar pattern of the equatorial SST bias (Fig. 1a, $2.00{ }^{\circ} \mathrm{C}$ in At13). FLX clearly reduces this bias (Fig. $1 \mathrm{~b}, 0.29^{\circ} \mathrm{C}$ in Atl3). Additionally and in contrast to STD, FLX is able to produce a cold tongue similar to observations (Fig. 2). An interesting detail of Fig. 2 is that the STD experiment, too, simulates Atl3 cooling between April and May, but fails to intensify this cooling to establish the cold tongue from May onwards. In contrast, Atl3 cooling in FLX really only starts in May-June. Effectively, cold tongue development in FLX lags behind observations by roughly 1 month (Fig. 2a). Nevertheless, heat flux correction clearly reduces the SST bias in the tropical Atlantic (Fig. 2b).

Richter and Xie (2008) and Richter et al. (2012) have shown in different CGCMs that the equatorial Atlantic SST bias is related to a bias in zonal surface wind in the western equatorial Atlantic, which in turn can be traced back to precipitation deficiencies of the models. Based on observations, Marin et al. (2009) argue that weak variability in WAtl zonal surface wind fails to precondition the basin-wide thermocline slope for the subsequent summer-the initial cooling of the cold tongue is hence weakened or delayed. In agreement with Richter et al. (2014a), a similar process could be at work in CGCMs: Spring zonal winds that are systematically too weak in the western equatorial Atlantic could inhibit seasonal thermocline shoaling in the eastern ocean basin and hence intense surface cooling during early boreal summer. 
(a) WAtI-U10

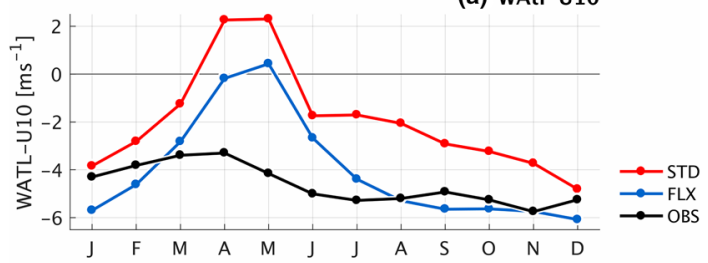

(b) Monthly U10-bias in WAtl

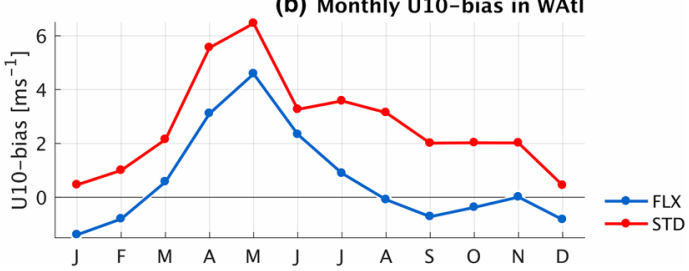

Fig. 3 Same as Fig. 2 but for zonal surface wind u10 in WAtl

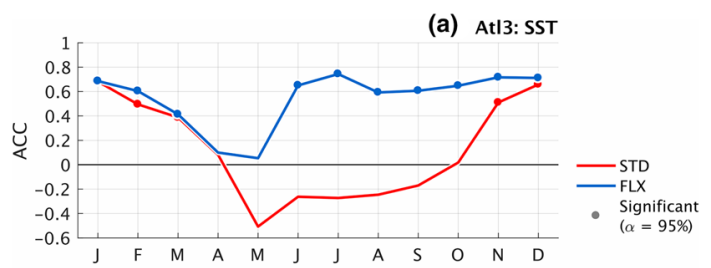

(b) WAtl: U10

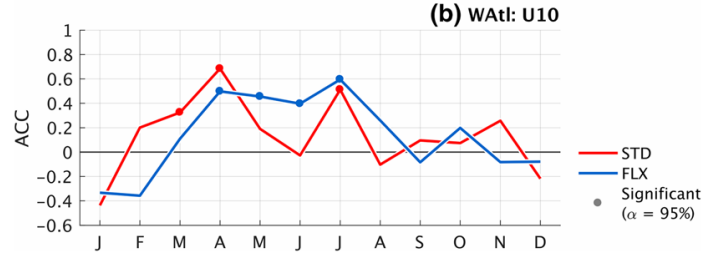

Fig. 4 Monthly anomaly correlation coefficients (ACCs) between ERA-Interim and the ensemble mean from the (red) STD and (blue) FLX experiments for a Atl3 SST and b WAtl u10 and the period 1981-2012

Here, we demonstrate that the KCM, too, develops a zonal wind bias in boreal spring that is, however, largely independent of the SST bias in the eastern ocean basin. Figure 3 shows that zonal surface wind in WAtl is greatly reduced in boreal spring relative to ERA-Interim. Surprisingly, this behaviour is hardly altered qualitatively in the FLX experiment, indicating that the zonal wind bias depends only weakly on eastern basin SST in the model. In agreement with the recent findings of Richter et al. (2014b) and Harlaß et al. (2015) we suspect that the zonal wind bias is at least partly due to the insufficient vertical resolution of the atmosphere model and related deficiencies in vertical momentum transport.

Additionally, we assess how the bias affects the KCM's ability to simulate observed SST and u10 variability. Figure 4 shows, for each calendar month, the anomaly correlation coefficient (ACC) between the ensemble means of the

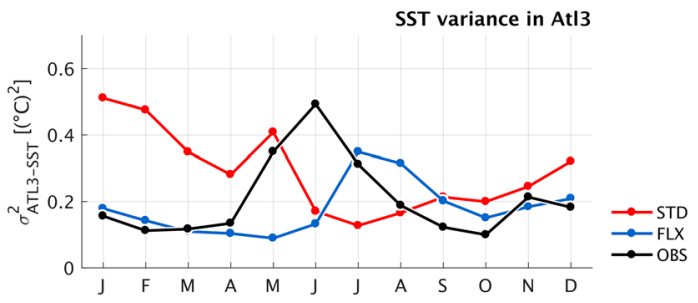

Fig. 5 Monthly SST variance in Atl3 for (black) ERA-Interim, (red) STD, and (blue) FLX

partially coupled KCM assimilation runs and ERA-Interim. Again, because the FLX and STD experiments only differ in whether they reduce the SST bias or not, differences in the "skill" of the assimilation runs to simulate the observed variability are due to the equatorial SST bias.

In agreement with Ding et al. (2015), bias reduction substantially increases the "skill" of the assimilation runs for boreal summer SST variability. This again supports the notion that the cold tongue is a crucial requirement for Atlantic Niño variability. Zonal wind variability, on the other hand, is only marginally improved by SST bias reduction in late boreal spring and early boreal summer.

An interesting aside with respect to the STD experiment is the strongly negative correlation coefficient for modelled and ERA-Interim SST during May. The value is almost -0.5 , indicating a relationship that could be interesting to explore further. However, analysing in depth the physical processes that give rise to such an outstanding relationship in the biased experiment is not the scope of this paper and should be addressed in future research.

\section{SST variance decomposition method}

Figure 5 shows the SST variance in the tropical Atlantic and its seasonality. In ERA-Interim, Atl3 SST variance is subject to a well-defined seasonal cycle that peaks in May-July, consistent with the peak phase of the Atlantic Niño. In agreement with Okumura and Xie (2006) a secondary peak occurs early in boreal winter.

The KCM struggles to reproduce the observed SST variance. While bias alleviation improves model performance, SST variance in FLX is too low and peaks 1 month late (Fig. 5). On the other hand, the STD experiment shows a seasonal cycle of SST variance that is almost the opposite of observations: Variance is high in boreal winter and decreases in boreal summer, reaching its minimum in July. Because the STD experiment is strongly biased in the tropical Atlantic (Figs. 1, 2), the cold tongue cannot develop in boreal summer and cold tongue variability is not captured. 
Next, we decompose total SST variance into a dynamically-driven and a stochastically-forced component. We term the variance of the dynamical (stochastic) portion of the signal the dynamical (stochastic) variance.

The canonical approach for such a decomposition is as follows: For an ensemble simulation, average the individual ensembles into the ensemble mean to constrain the uncertainty of the simulation (for example due to imperfect initial conditions or model physics). For a given signal, equate the ensemble mean with the dynamical-i.e. predictable-contribution to the signal. The difference between the ensemble mean and the individual ensemble integrations represents the noise of the climate system - the stochastic, i.e. unpredictable, contribution to the signal. Note that in our specific case, the ensemble mean of a simulation is the dynamical response of the partially coupled model to the imposed wind stress anomalies.

The observed climate record, however, corresponds to a single realization of a climate simulation. Decomposing variance via ensemble averaging is not possible. To nevertheless diagnose observed dynamical SST variance, we use an alternative, empirical approach. Below, we first outline the basic concept of our approach and then present the technical details of the SST decompositions discussed in Sects. 5 and 6.

Conceptually, we model dynamical SST variability with the help of linear empirical models that employ multiple predictors. The idea is very simple: We identify feedbacks that are involved in growing SST anomalies in the tropical Atlantic and attempt to capture the effect of these feedbacks in empirical models. Lübbecke and McPhaden (2017) have used a similar approach to diagnose and compare feedback strengths in the equatorial Atlantic and Pacific oceans. The difference here is that we use more than one predictor and hence attempt to combine a number of feedbacks into a single model of SST. Because we consider feedbacks that are related to dynamical processes in the equatorial system, we equate the portion of the full SST anomaly that is captured by our empirical models with the dynamical SST anomaly. The residual SST anomaly is our stochastic SST anomaly.

For example, consider a set-up in which we use the thermocline feedback as the dynamical core of SST variability (for simplicity's sake, only consider a single feedback for now). To diagnose the observed dynamical SST variance, we use observed thermocline depth in the eastern equatorial Atlantic to model ERA-Interim SST variability in the same region. Note that our empirical models are of the simplest possible nature: We use linear regression. Once we have built the empirical model of (thermocline-driven) dynamical SST, we use this model to "hindcast" SST based on the time series of thermocline depth. The result of this empirical hindcast is our dynamical SST. When we subtract the (thermocline-driven) dynamical SST from the full SST of our original ERA-Interim dataset, the residual is the stochastic SST anomaly that can not be explained by thermocline depth variability. We then have three time series of SST: The original ERA-Interim SST, dynamical SST based on the thermocline feedback, and the residual stochastic SST. The SST variances that we are interested in are obtained by calculating the variances of these three SST time series. Note that our decomposition approach heavily relies on empirical linear models, but that the resulting decomposition of the SST variance is not linear, i.e., the full SST variance is not the sum of the stochastic and dynamical SST variance. (The basic decomposition of the SST anomaly, however, is.)

Here, we use the Bjerknes feedback as the dynamical framework for our empirical models of dynamical SST. With respect to the first and third elements of the Bjerknes feedback, i.e. the SST-zonal wind relationship and the surface-subsurface coupling between thermocline depth and SST, we choose zonal wind variability (u10) in WAtl and thermocline depth variability in Atl3 as predictors for SST. ${ }^{1}$ Because the ERA-Interim reanalysis does not provide thermocline depth, we use AVISO sea surface height ( $\mathrm{SSH}$ ) in Atl3 as a stand-in. SSH is a reasonable proxy for thermocline depth in Atl3, since Cane (1984) showed that SSH, thermocline depth, and upper ocean heat content are tightly related in the equatorial oceans. This in agreement with the notion that the tropical oceans can be considered as a 1.5-layer system (e.g. Keenlyside and Latif 2007).

To resolve the seasonality of dynamical and stochastic SST variability in the equatorial Atlantic, we build empirical models of dynamical SST for each calendar month. We do this separately for ERA-Interim/AVISO (our "observations") and all ensemble members of the STD and FLX experiments. The resulting SST variance is (1) for ERA-Interim: the variance of the time series of dynamical and stochastic SST, and (2) for the KCM experiments: the variance of the SST time series that concatenates the time series of all ensemble members for the respective KCM experiment.

In this study, we build empirical models via least-squares fitting. During the building process, however, we use two different approaches.

\footnotetext{
${ }^{1}$ Note that an alternative approach is to identify feedbacks that lend positive growth to SST anomalies in Atl3 and choosing as SST predictors the variables that are associated with these feedbacks. Dijkstra (2006) discusses the Ekman and zonal advection feedbacks as suitable feedbacks for our purpose. However, we prefer to motivate our decomposition with the Bjerknes feedback, since it represents a more integrated view of coupled variability in the equatorial oceans. For completeness' sake, the Ekman feedback can be associated with the third element of the Bjerknes feedback, i.e. surface-subsurface coupling in the eastern ocean basin, while the zonal advection feedback is related to the two-way relationship between SST and u10 and not strictly a part of the Bjerknes feedback concept.
} 
1. In the first approach, we prescribe the predictors that the empirical model should use. This is the most straightforward approach, and it ensures that all models always use $\mathrm{SSH}$ and $\mathrm{u} 10$ as predictors, regardless of whether they are "necessary" for the prediction or not. Our predictors are a linear combination of the SSH and $\mathrm{u} 10$, and our simple empirical models have the form $s s t \sim s s h+u 10$.

2. In the second approach, we do not prescribe the exact form of the empirical model but a pool of predictors from which an algorithmic model adjustment chooses the "ideal" combination of predictors for the given dataset and calendar month. From this pool of possible predictors, algorithmic model adjustment sequentially builds a whole range of empirical models for the same response variable-dynamical SST, in our case-and seeks to identify the model that performs best in terms of model accuracy and overfitting (e.g. Draper and Smith 1998). Based on a selection criterion, the adjustment algorithm ranks the models. The final adjusted model is the model that beats the competing models in the adjustment sequence. An interesting feature of algorithmic model adjustment is that it allows non-linear combinations of predictors, such as quadratic terms or predictor products.

For example, the adjustment process might start with the simple model $s s t \sim s s h+u 10$. It then removes the predictor u 10 and ranks the model $s s t \sim s s h$ relative to the original model. It might then proceed to test the non-linear predictor combinations $s s t \sim s s h^{2}$ and $s s t \sim \frac{s s h}{u 10}$ to arrive at the conclusion that $s s t \sim s s h$ is the "best" model in terms of the chosen selection criterion.

We implemented the algorithmic model adjustment with the function step() of Matlab version 2016b. For more technical details about the adjustment process, please refer to the extensive Matlab documentation. ${ }^{2}$

In this study, we apply model adjustment to identify the simplest form of our empirical models. Three outcomes are possible: (1) model adjustment reduces model complexity and removes one of our two predictors. This indicates either that the co-variability between our predictors is strong during the respective month and that using either of them provides sufficient information to produce reasonable dynamical SST; or that the removed predictor does not have a strong impact on SST variability during this month. (2) Model adjustment keeps both predictors in a linear combination.

\footnotetext{
2 https://de.mathworks.com/help/matlab/. The exact documentation of the step () -function for the linear model-class can currently be found here: https://de.mathworks.com/help/stats/linearmodel.step. html.
}

(3) Model adjustment increases the complexity of the model by adding a non-linear predictor term, i.e. a quadratic term or a product of SSH and u10. This could indicate that SST variability during the respective month is more complex and requires further constraints in the form of additional predictors. Because non-linear predictor terms are the only possible addition to the model in the context of our model adjustment, the algorithm evaluates them. Another possibility is that the non-linear terms capture actual non-linear interaction in the climate system.

Our model selection criterion is the sum of squared errors (SSE). Because the number of our data points $(20)^{3}$ is large compared to the size of the initial predictor pool (2), it is unnecessary to penalise the number of predictors to avoid overfitting. This could be achieved by basing selection on the Akaike or Bayesian information criteria instead of on SSE. Since we do not intend to use our SST models for true forecasting purposes, we do not conduct extensive cross-validation.

In this study, we discuss three different empirical models of dynamical SST: (1) The fixed model of dynamical SST corresponds to the straight-forward model discussed above. It uses the empirical model of the form $s s t \sim s s h+u 10$ . Model adjustment is not allowed. (2) Single models use either SSH or u10 as a single predictor for dynamical SST, i.e. they are of the form $s s t \sim s s h$ or $s s t \sim u 10$. They help to identify periods during which the respective feedback is active in isolation. They offer a focused interpretation of the impact of either $\mathrm{SSH}$ or $\mathrm{u} 10$, but ignore their interaction in the complex tropical climate system. (3) The adjusted model employs algorithmic model adjustment, based on the initial predictors SSH and u10. Note that model adjustment is done for observations only, and the adjusted models obtained from observations are then used to estimate dynamical SST from the KCM experiments. An alternative approach would be to apply model adjustment to the individual experiments as well. However, using these "native" adjusted models yields results that are only marginally different (not shown). For the purpose of this study, we thus only use adjusted models that were derived from observations. For all models, the analysis period to fit the models is short: 1993-2012, the overlap between AVISO SSH-data and the rest of our data.

To test the validity of our approach, we conduct SST variance decompositions with both the ensemble averaging approach outlined above and the empirical model approach for the STD and FLX experiments. Figure 6 illustrates the two approaches. Thin and thick coloured lines show the SST

\footnotetext{
${ }^{3}$ For each month, regardless of whether the empirical models are built for observations or the KCM experiments, use the overlapping period of ERA-Interim (SST, u10) and AVISO (SSH), i.e. 19932012 - this gives time series that all have a length of 20 data points.
} 
(a) Fixed: Dynamical

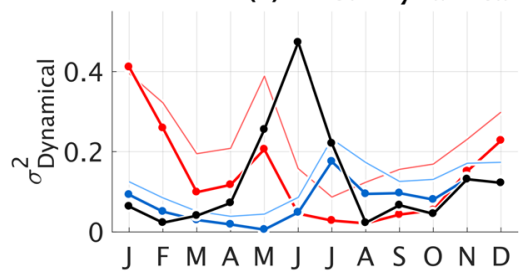

(b) Fixed: Stochastic

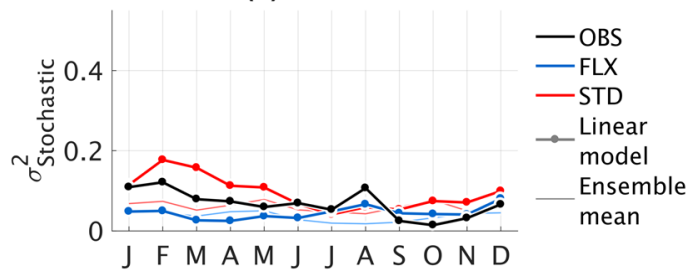

Fig. 6 Atl3 SST variance decomposition into a dynamical and b stochastic SST variance for (black) ERA-Interim/AVISO, (red) STD, and (blue) FLX. Stochastic SST variance is the variance of the residual of total SST after dynamical SST has been subtracted. Dynamical SST is subtracted from each ensemble member individually, and the time series of residual (stochastic) SST are concatenated before the

variances based on ensemble averaging and our fixed empirical models, respectively. Overall, results are comparable for the STD and FLX experiments. Empirical modelling underestimates dynamical SST variance (Fig. 6a) while simultaneously overestimating stochastic SST variance (Fig. 6b). This suggests that our simple empirical approach fails to capture all processes that are relevant to dynamical SST variability. On the other hand, qualitative differences between the two seasonal distributions of dynamical SST variability are small, regardless of the presence of the bias.

We conclude that empirical modelling is a reasonable alternative to the ensemble mean approach.

Lastly, we point out a limitation of our models that is in line with the discussion of the Bjerknes feedback presented in the introduction. Our SST variance decomposition approach allows us to identify periods of the seasonal cycle when the dynamical Bjerknes feedback contributes substantially to SST variability in At13. It would be easy to conclude from our analysis that dynamical processes contribute to SST variability and that these dynamical processes must hence be associated with enhanced SST predictability. However, such a conclusion might be overly optimistic. The reason is that our SST decomposition approach relies on the empirical method of linear regression. When our empirical models pick up a statistical relationship between SST and our two predictors SSH and u10, they do not automatically provide a clear causality or "forcing direction". Consider again, for example, the relationship between SST and u10, and imagine a scenario in which SST is driven by ocean processes that are possibly off-equatorial in nature, such as variability associated with the subtropical cells. In the coupled equatorial system, the atmosphere would react to the oceaninduced SST variability and our empirical models would pick up a statistical co-variability between SST and u10 that would be partly reflected in our SST decomposition-even though u10 in this idealized example was not fundamental in causing the SST variability in the first place. From this example, it is clear that the interpretation of our results with variance is calculated. Thick lines denote SST variance decomposition based on the empirical models for dynamical SST (see text for details). Thin lines for FLX and STD denote SST variance decomposition based on ensemble averaging. The empirical model is the fixed model

respect to SST predictability might not be straightforward. However, keep in mind that the scope of this study is not to measure SST predictability, but to assess when dynamical processes are active in the equatorial Atlantic.

\section{Seasonality of dynamical SST Variance in the tropical Atlantic}

Figure 6 shows the dynamical and stochastic SST variances from our fixed model for the equatorial Atlantic; Fig. 7 shows the ratio of the two variances. Results are displayed for observations and the two KCM experiments.

Observations (black): dynamical SST clearly dominates observed SST variance during early boreal summer (May-July, Fig. 6a). Dynamical SST variance then is roughly 4-7 times larger than the stochastic contribution to total SST variability (Fig. 7). A secondary peak occurs during October and November. These two periods of enhanced dynamical SST variability are separated by phases during which stochastic SST variance is larger than dynamical SST variance. This is the case in JanuaryMarch and again in August, when dynamical SST variance vanishes and observed stochastic SST variance reaches its peak. Note that observed stochastic SST variance is much less variable over the course of the year (Fig. 6b). This

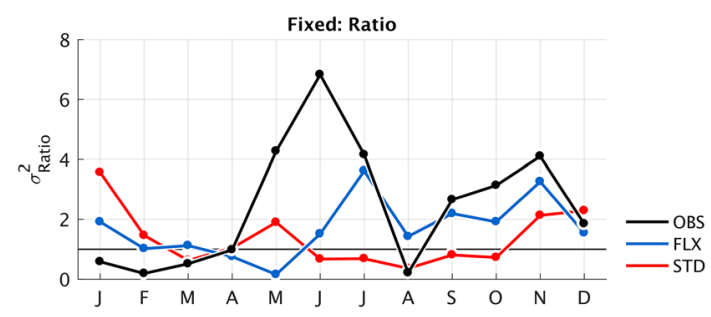

Fig. 7 Ratio of dynamical and stochastic SST variance in the fixed model for Atl3. Ratios are shown for (black) ERA-Interim/AVISO, (red) STD, and (blue) FLX 
suggests that stochastic SST variance is indeed driven by processes that are independent of seasonal processes-it represents noise.

Comparing dynamical SST variance from the fixed model (Fig. 6a) with total SST variance (Fig. 5) shows a generally good agreement. In August, however, when dynamical SST variance vanishes according to our empirical models, total SST variance continues to decrease evenly. Here, stochastic SST variance contributes to total SST variability (Fig. 6b).

The overall similarity between the total and dynamical SST variance suggests that the seasonal cycle of total SST variability in the tropical Atlantic is largely shaped by the variable dynamical contribution.

The dynamical and stochastic SST variances for the model experiment FLX are comparable to observations (blue). Dynamical SST variance peaks in boreal summer and again, more weakly, in early boreal winter (Fig. 6a). However, the timing of the dynamical SST variance peaks does not match observations. The summer peak lags behind observations by 1 month and is strongly reduced in amplitude. The absolute minimum of dynamical SST variance occurs in May-when observed dynamical SST variance is already high and contributes substantially to the overall boreal summer peak. Additionally, dynamical SST variance does not decrease as strongly in August, and the secondary peak is hardly a peak at all.

One reason for these shortcomings in the FLX dynamical SST variance is most likely related to systematic differences between the observed and heat-flux corrected seasonal cycles (Fig. 2). While the bias correction strongly reduces the annual mean bias (Fig. 1), it is not able to fully constrain the model to the observed seasonal cycle. Instead, cold tongue development in the FLX experiments sets in systematically too late and lags behind the observed cold tongue development by about 1 month. The observed and simulated seasonal cycles only converge in August, when the cold tongue is fully developed and starts to dissolve. In the framework of our empirical models, this delay in cold tongue development explains the absence of dynamical processes during May, because these processes depend on the presence of the cold tongue. However, once the cold tongue is established, the feedbacks set in and contribute to dynamical SST variability. Stochastic SST variance is similar to observations in both magnitude and seasonality (Fig. 6b). The ratio of the variances in the bias-corrected model run bears similarities to observations but lacks the clear double peak structure (Fig. 7), because dynamical SST variance does not vanish in FLX. One reason could be that, similar to the delayed cooling during the onset of the cold tongue, initial warming in August-September is weaker in FLX than in observations $\left(0.61\right.$ and $0.20{ }^{\circ} \mathrm{C}$ month $^{-1}$ in ERA-Interim and FLX, not shown). In contrast to observations-where the surface-subsurface coupling in Atl3 is disrupted in August-, the thermocline feedback stays active in FLX (see Sect. 6).

The STD experiment does not capture the observed dynamical SST variance distribution (red). On the contrary: With the exception of May, when the eastern equatorial Atlantic starts to cool in STD but then aborts the cooling to develop the strong boreal summer bias (Fig. 2), dynamical SST variance is at its lowest in boreal summer and increases in boreal winter. This is most likely because the equatorial cold tongue dissolves in late boreal summer and the background states of observations, FLX, and STD become more similar. The STD SST bias decreases and our empirical models operate on comparable conditions, resulting in dynamical SST variances in the STD experiment that are similar to observations in boreal fall and early boreal winter. Note that while dynamical SST variance appears to be rather high in STD during late boreal winter and even comparable in magnitude to observations, stochastic SST variance in STD is systematically higher than in observations throughout most of the year (Fig. 6). The resulting SST variance ratio (Fig. 7) shows that dynamical processes in STD almost never have the same impact on SST variability as in FLX or observations. An exception is January-February, when STD simulates dynamical contributions to SST variability that dominate stochastic contributions.

These findings suggest that the background state-i.e. the seasonal cycle of the system-is crucial for a realistic simulation of dynamical SST variance. While the FLX experiment is not perfect, it is clearly an improvement on the STD experiment that lacks the Atlantic cold tongue in its background state.

Additionally, our findings show that observed SST is dominated by dynamical SST variance in May-July. This coincides with the peak phase of the Atlantic Niño and suggests that a major part of the Atlantic Niño-variability could indeed be caused by dynamical-but not necessarily predictable - processes. This appears to be at odds with the results of Nnamchi et al. (2015), who find in CMIP3based slab model simulations (i.e. simulations that omit ocean dynamics) that Niño-like variability in the equatorial Atlantic can be produced by stochastic atmospheric forcing alone. To explain this, Nnamchi et al. (2016) argue that the Atlantic Niño is the equatorial manifestation of the more general South Atlantic Ocean SST Dipole (SAOD). They demonstrate that SOAD-variability is related to the variability of the South Atlantic (St Helena) Anticyclone and is sustained by the wind-evaporation-SST feedback. While this is in agreement with Lübbecke et al. (2014)'s work on the relationship between the Atlanic Niño and the St Helena Anticyclone, it still does not fully explain how our results tie in with Nnamchi et al. (2015). 
Fig. 8 Dynamical Atl3 SST variance based on a the single SSH model, and $\mathbf{b}$ the single u10 model. SST variances are shown for (black) ERA-Interim/ AVISO, (red) STD, and (blue) FLX

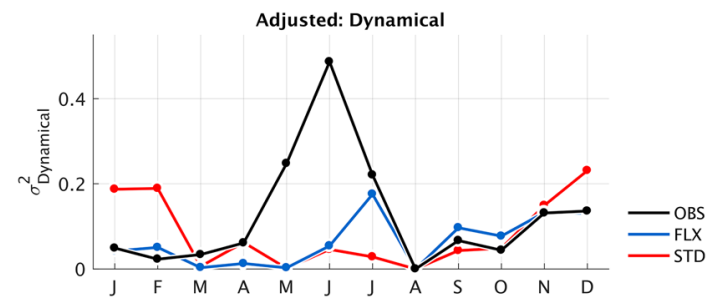

Fig. 9 Dynamical Atl3 SST variance based on the adjusted model for (black) ERA-Interim/AVISO, (red) STD, and (blue) FLX

We propose that reality is a mixture of both a dynamically and stochastically driven Atlantic Niño. Specifically, we find that ocean dynamics are important to grow Atlantic Niño events in early boreal summer. This does not contradict the notion that initial anomalies in the equatorial Atlantic need to be "excited" by stochastic forcing that in turn could be related to the St Helena Anticyclone. Once these initial anomalies develop in late boreal spring, the presence of the cold tongue allows the Bjerknes feedback to amplify them.

However, we point out that we are still not able to fully reconcile our results with Nnamchi et al. (2015)'s findings with respect to the question how a slab ocean can not only respond to initial atmospheric perturbations but also help to grow them. An interesting future analysis could address this apparent discrepancy by assessing the relative impact of both the dynamical Bjerknes feedback and the thermodynamic wind-evaporation-SST feedback on tropical Atlantic SST anomaly growth during boreal summer.

To complement the analysis above, we repeat our analysis using different sets of predictors in our empirical models. Figure 8 shows the dynamical SST variance based on the single SSH and u10 models; Fig. 9 shows the same for the adjusted model. (b) Single U10: Dynamical

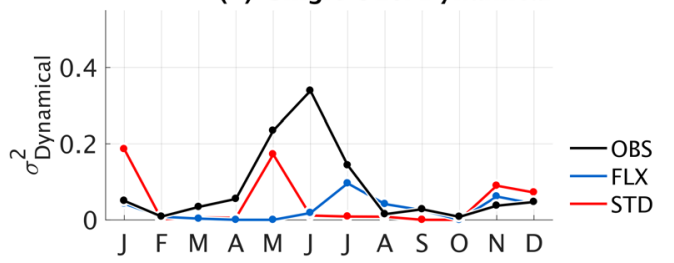

Comparing Figs. 6a and 8a, b, shows that observed dynamical SST variances (black) of the single SSH and u10 models share the prominent boreal summer peak with the fixed model. This suggests that, even in isolation, both zonal surface wind and thermocline processes are involved in establishing the boreal summer variability of SST. In boreal winter, the single u10 model does not contribute to dynamical SST variance.

The adjusted model produces SST variances that are very similar to the fixed model (Figs. 6a, 9). Table 1 shows the predictors that the algorithmic model adjustment chose to model observed SST for each month. Late boreal winter SST variability is generally well modelled by either SSH or u10, indicating prevalent co-variability between SSH and $\mathrm{u} 10$ or that the excluded predictor does not contribute substantially to constraining dynamical SST. June and July require more than one predictor and even non-linear interaction of SSH and u10 in June. This suggests that variability during the early stage of cold tongue development can be mainly explained by thermocline variability, while the cause of variability during the growth phase of the cold tongue is more complex. Then, it does not suffice to isolate a single feedback. Rather, to explain Atlantic Niño variability during climatological cold tongue growth, a number of factors have to be considered.

In August, model adjustment chooses to use no predictor. This means that in our statistical framework, observed August SST variability is unconstrained by SSH and u10. SSH and u10 start to contribute to SST variability again in September. In December dynamical SST again depends on non-linear interactions.

Overall, our analysis suggests that the relative importance of either thermocline processes or zonal surface wind varies over the course of the year in the observed climate system. Especially during the early stages of cold tongue

Table 1 Predictors of dynamical SST for each calendar month in At13 based on observations

\begin{tabular}{|c|c|c|c|c|c|c|c|c|c|c|c|}
\hline $\mathbf{J}$ & $\mathrm{F}$ & M & A & $\mathrm{M}$ & $\mathrm{J}$ & $\mathrm{J}$ & A & $S$ & $\mathrm{O}$ & $\mathrm{N}$ & $\mathrm{D}$ \\
\hline & SSH & & SSH & SSH & SSH & $\mathrm{SSH}$ & & SSH & SSH & SSH & $\mathrm{SSH}$ \\
\hline \multirow[t]{2}{*}{$\mathrm{u} 10$} & & u10 & & & u10 & $\mathrm{u} 10$ & & u10 & & & u10 \\
\hline & & & & & prd & & & & & & prd \\
\hline
\end{tabular}

The basic predictors are SSH in Atl3 and 10 m zonal wind anomalies (u10) in WAtl. "prd" refers to a product of the two individual predictors and indicates non-linear interaction in the climate system 
development, our empirical models chose not a single predictor but a combination of them, while August is basically unpredictable by statistical means.

Single and adjusted models that are based on FLX and STD produce different dynamical SST variances (Figs. 8, 9). For FLX, the same 1 month lag in boreal summer is present that has already been identified in the fixed model.

\section{Feedback strengths in the tropical Atlantic}

Our SST decomposition approach is based on the dynamical framework of the Bjerknes feedback. For this reason, we now take a closer look at the Bjerknes feedback-both observed and modelled - and its three elements in the tropical Atlantic. Recall that the three relationships that make up the closed Bjerknes feedback in our framework are (1) Atl3 SST produces WAtl u10 variability, (2) WAtl u10 variability is translated into Atl3 thermocline-here: $\mathrm{SSH}$ - variability via equatorial wave dynamics, and (3) Atl3 SSH positively feeds back to Atl3 SST and lends growth to the initial SST anomaly.

Here, we first consider the instantaneous Bjerknes feedback, and then analyse how the feedback strengths change when we allow lagged relationships for the individual feedback elements. In particular, we incorporate lagged relationships into the building process of our empirical models and assess their impact on the seasonal distribution of dynamical SST variance. This measures the robustness of our results.

We begin with the instantaneous Bjerknes feedback, which is made up of instantaneous relationships of the form (1) to (3). With this constraint, May SST is only able to affect May u10, May u10 is only able to affect May SSH, and so on. Figure 10 assesses the strength of the instantaneous Atlantic Bjerknes feedback in terms of correlation strengths between the relevant variables. Note that for the partially coupled KCM experiments, we use the model u10 for relationship (1), but observed u10 when we assess the relationship strength between u10 and SSH in relationship (2).

It is clear that the strength of the Bjerknes feedback elements varies considerably over the course of the year. In agreement with Keenlyside and Latif (2007) and Deppenmeier et al. (2016), all observed feedback elements are generally strongest in early boreal summer, establishing a closed Bjerknes feedback loop in May-July (Fig. 10a). This coincides with both the peak of total SST variance (Fig. 5) and the active phase of the Atlantic Niño, supporting the hypothesis that Atlantic Niño variability is related to the Bjerknes feedback. Note that the coupling between the ocean subsurface and surface that is captured in the SST-SSH relationship is strong in boreal fall as well but dips in August. This implies that the communication between surface processes

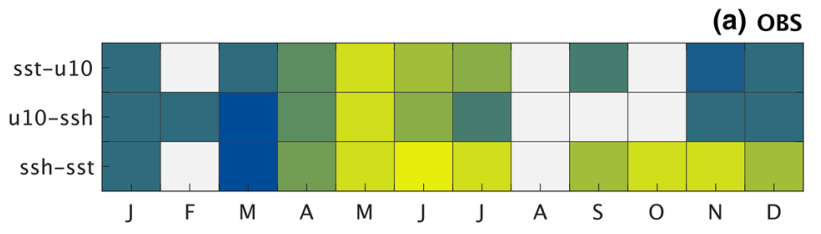

(b) FLX

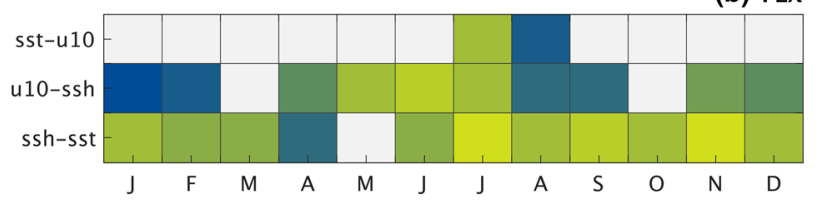

(c) STD

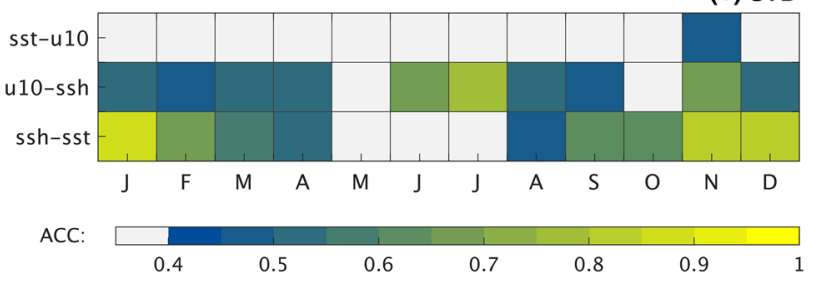

Fig. 10 Anomaly correlation coefficients between SST, u10, and SSH for each calendar month in a ERA-Interim/AVISO, b FLX, and c STD. Because our model experiments are partially coupled, we use observed $\mathrm{u} 10$ to assess the u10-SSH-relationship (second rows). For the SST-u10-relationship (first row), on the other hand, we use the model winds. SST and SSH anomalies are averaged in Atl3, u10 anomalies in WAtl. ACC values that are not significantly different from 0 at the $95 \%$ level according to a Student $t$ test are shown in grey

and the ocean interior temporarily fades in late boreal summer, disrupting the Bjerknes feedback loop.

The KCM experiments struggle to capture the observed relationships that form the instantaneous Bjerknes feedback in the tropical Atlantic (Fig. 10b, c). The SST-u10 relationship is hardly captured at all in either experiment. A single exception is July in the FLX experiment: Here, the KCM captures a relationship that is comparable to observations and is able to simulate a closed Bjerknes feedback loop. As in observations, this coincides with the occurrence of the peak in total SST variance (Fig. 5). Note that FLX simulates a reasonable SSH-SST relationship in boreal winter, but fails to produce this crucial relationship in May. Again, we suspect that the bias in the onset of the cold tongue is responsible for this behaviour. Because cold tongue development only really sets in in June in FLX (Fig. 2), the thermocline cannot communicate with SST in May. FLX fails to establish the observed relationship. For the same reason, STD is not able to produce the SST-SSH relationship of the instantaneous Bjerknes feedback in boreal summer.

Our results agree with the observations-based part of Deppenmeier et al. (2016)'s analysis of the Bjerknes feedback in the tropical Atlantic. However, while Deppenmeier et al. (2016) point out that it is mainly the relationship between upper ocean heat content (approximated by our 
(a) SST vs U10

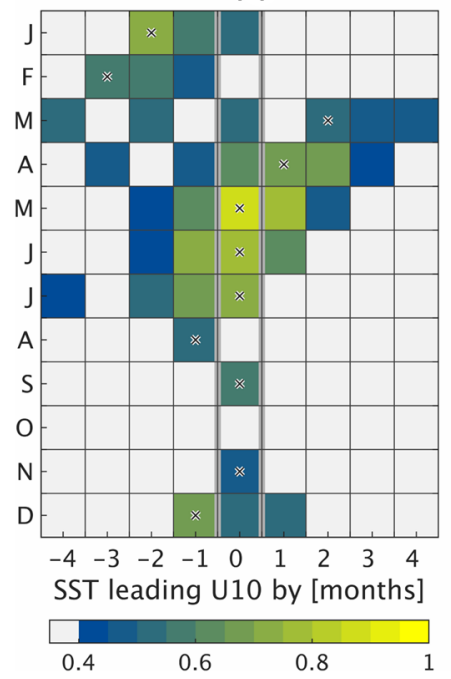

(b) U10 vs SSH

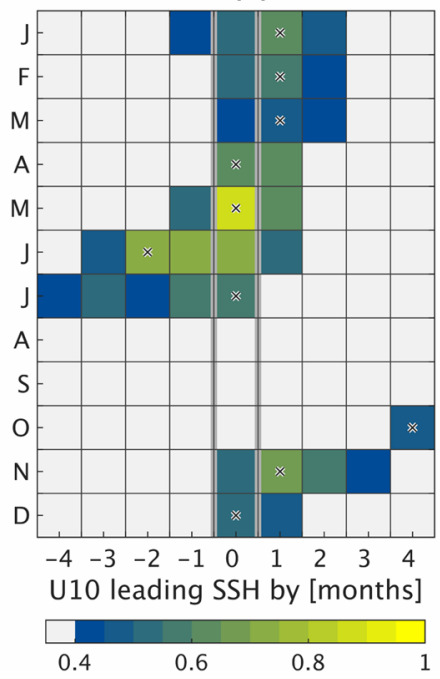

(c) SSH vs SST

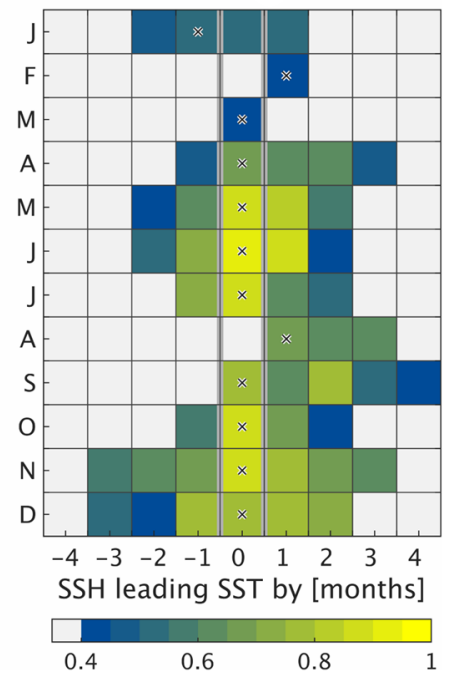

Fig. 11 ERA-Interim/AVISO-based monthly stratified anomaly cross correlation for a Atl3-SST vs WAtl-u10 [corresponds to Bjerknes feedback element (1)], b element (2): WAtl-u10 vs Atl3-SSH, and c element (3): Atl3-SSH vs Atl3-SST. Only ACC values that are significantly different from 0 at the $95 \%$ level are shown as coloured shading. To calculate the cross correlation values for each month, we fix the "response agent" of the respective element (the second element in the figure titles) in time and correlate it sequentially with the monthly time series that corresponds to each lag. For the January-analysis of

SSH) and SST that is too weak in CMIP5-simulations, the KCM's problems are mainly related to the SST-u10 relationship, possibly due to the low atmospheric vertical resolution. In the current version of the KCM, FLX produces a closed Bjerknes feedback loop only in July (May-July in observations) - the model's ability to produce a Bjerknes feedback akin to observations is severely impaired by the delayed onset of the cold tongue.

In summary, our analysis shows that a relationship exists between the equatorial Atlantic bias and the degree to which the instantaneous Atlantic Bjerknes feedback is active in summer. The instantaneous feedback clearly relies on the presence of the cold tongue to make use of it's potential.

However, previous studies have shown that both the Atlantic and Pacific Bjerknes feedbacks do not necessarily operate instantaneously (see Introduction). For this reason, we now consider a lagged Bjerknes feedback. We first assess the observed lagged relationships in the tropical Atlantic, and then repeat our SST variance decomposition, this time allowing for lagged relationships between SST and the two predictors SSH and u10. We assess the degree of lag for each of the three Bjerknes relationships via a cross-correlation analysis for each month.

For this to work, we assume that each Bjerknes feedback element describes a relationship of clear causality: one quantity "forces" the other. In element (1), for example, element (3), for example, the correlation of January SST with the following May is given in the January rows at a lag of -4 months, and so on. Negative lags indicate that SST variability precedes SSH variability ("SST leads SSH"), positive lags indicate that SSH leads SST. Calendar months are indicated on the y-axis. Black crosses indicate the lag-shown on the x-axis-at which the ACC value of the respective element is maximum. For example, in element (3), August-SST is strongest related to SSH when SSH leads by 1 month, i.e. AugustSST is strongest correlated to July-SSH

SST "forces" u10. As discussed previously, this concept is highly idealized and does not realistically describe the entire spectrum of atmosphere-ocean interaction in the equatorial Atlantic. However, in the framework of our lagged Bjerknes feedback, we will make use of the idealized relationships and refer to the involved quantities of a Bjerknes feedback element either as the "forcing" or "response" agents.

In our cross-correlation analysis for each calendar month and Bjerknes feedback element, we fix the response agent to the calendar month and correlate it sequentially with the forcing agent of all relevant lags. Our maximum lag is \pm 4 months. As an example, consider Bjerknes feedback element (1). SST is the forcing, u10 the response agent. For the cross correlation analysis of January, we select the time series of monthly mean WAtl u10 in January. Then, for all lags, we select the corresponding SST time series and correlate it with January $\mathrm{u} 10$. This means that for a lag of -4 months, January u 10 is correlated with May SST, for -3 months with April SST, and so on. Note that a negative lag indicates that, in this example, the chosen u 10 variability precedes the SST variability, i.e. u10 "leads" SST. For positive lags, SST leads u10.

Figure 11 shows the results for the observed tropical Atlantic. Color shading indicates anomaly correlation coefficients that are significantly different from 0 at the $95 \%$ level. A lag of 0 months (from here-on "lag 0") is framed 
(a) Fixed: Dynamical, leading lags

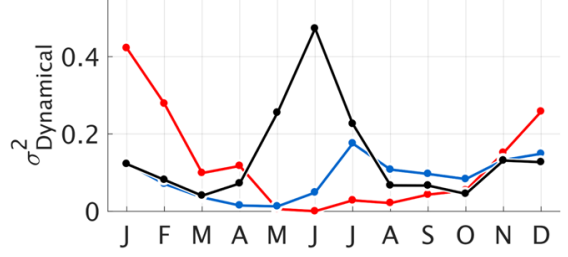

Fig. 12 Same as Fig. 6a, but including lagged relationships when building the empirical models of dynamical SST. The chosen lags correspond to the maximum correlation values. For observations, these "peak months" are indicated by black crosses in Fig. 11. a Posi-

by grey vertical bars for better visibility. Note that lag 0 in Fig. 11 is identical with the corresponding instantaneous relationship shown in Fig. 10. Black crosses indicate the lag for which the relationship in terms of the ACC is strongest for the considered calendar month and Bjerknes feedback element. For the remainder of the study, we refer to these lags as "peak lags".

Figure 11 shows that the Bjerknes feedback in the tropical Atlantic is essentially instantaneous during the peak time of the Atlantic Niño from May to July. (This is not necessarily the case during other seasons, including during boreal spring, when enhanced western tropical Atlantic wind stress has been shown to precondition the development of the cold tongue in boreal summer, e.g. Marin et al. 2009). This agrees with Lübbecke et al. (2014), who demonstrate that the relationship between SST and wind power anomalies in the tropical Atlantic is basically symmetrical around lag 0 . An interesting interpretation of this finding is offered by Frankignoul et al. (1977). They argue that a positive feedback produces a clear signature in a cross-correlation analysis, with peak ACC values at lag 0 that decrease symmetrically for increasing lags of both signs. In such a positive feedback, the involved agents reinforce each other and lend growth to small perturbations. This interpretation of a positive feedback supports the notion that the Bjerknes feedback in the tropical Atlantic consists of three partial feedbacks that each, in terms of monthly means, act more or less simultaneously as positive feedbacks during boreal summer.

Note that our cross-correlation analysis appears to be at odds with earlier studies that find that wind variability consistently leads SST variability in the tropical Atlantic (e.g. Keenlyside and Latif 2007; Richter et al. 2013). Two important details that could contribute to this apparent discrepancy are (1) that these studies used different datasets and periods for their analysis, and (2) that their evidence is based on yearly or seasonal data. Here, on the other hand, we stratify our data into monthly means and present cross-correlation analysis for individual calendar months. We chose this approach in agreement with recent findings (e.g. Lübbecke and McPhaden 2017) that stress how relevant short time (b) Fixed: Dynamical, full lags

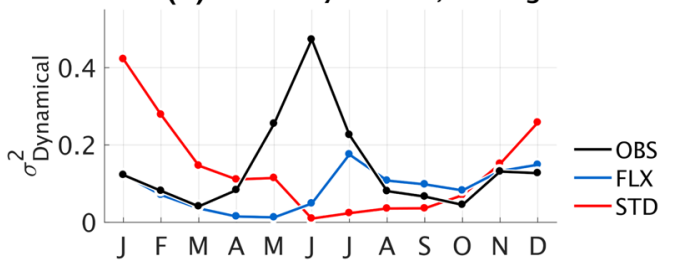

tive lags only, i.e. the predictors are allowed to lead SST only. When SST leads the predictor, the instantaneous relationship-i.e. lag 0 - is used. b Full lags, i.e. Predictors can lead and lag SST

scales of 1 month and possibly even less are for establishing the tropical Atlantic seasonal cycle. Temporally averaging (monthly) data over as little as 2 months already runs the risk of blurring important signals in the tropical Atlantic.

Returning to our results, we find that both in the instantaneous and the lagged analysis (Figs.10,11), the strongest relationship throughout the year is related to surface-subsurface coupling. Wind-related feedback elements are active less consistently.

Next, we incorporate the lagged relationships into our linear models of dynamical SST. We diagnose each month's peak lags separately for all datasets and all ensemble members. ${ }^{4}$ Once we identified all peak lags, we rebuild our empirical models of dynamical SST and replace the monthly time series of the predictor with the time series that corresponds to the appropriate peak lag. For example, for observations and the SST-SSH relationship in February, we do not use February but January SSH to build our empirical model of dynamical SST, because the peak lag of February is +1 (Fig. 11c), indicating that SSH leads SST variability by 1 month for February SST.

When including the peak lags into our dynamical models, we distinguish two cases: (1) empirical models that incorporate lagged relationships only when the predictor variables lead SST. The assumption here is that we are interested in the response of SST to a prescribed forcing and that this response cannot, physically, precede the forcing. (2) All peak lags are used when building the empirical models, including those when, statistically, SST leads its own predictors. The resulting dynamical SST variances are shown in Fig. 12.

\footnotetext{
${ }^{4}$ An important detail is that for feedback element (1), the relationship between SST and u10, we swap the forcing and response roles of the two agents while performing the cross correlation analysis. The reason is that we use $\mathrm{u} 10$ as a predictor of dynamical SST and hence implicitly assume that $\mathrm{u} 10$ is, to some degree, directly forcing SST variability. While this is not strictly in line with the conceptual model of the Bjerknes feedback, it is physically consistent with our empirical modelling framework.
} 
A comparison with the distribution of the dynamical SST variance of the unlagged case (Fig. 6a) immediately shows that the impact of lagged relationships is negligible at best (this is true for both observations and the model experiments, indicating that lagged relationships in FLX and STD do not substantially influence dynamical SST variance in the two experiments, even though the lag relationships are most likely not identical with their observed counterparts). The simple reason for this is that the three Bjerknes feedback elements are essentially instantaneous when they are strong and only stray from lag 0 peak lags when they decrease (Fig. 11). This means that Bjerknes feedback elements in the tropical Atlantic are mostly instantaneous when the tropical Atlantic is dynamically "active", i.e. during late boreal spring and early summer and again in early boreal winter.

\section{Summary and discussion}

We assess the impact of the equatorial Atlantic bias in coupled climate models on their ability to realistically simulate the variability and dynamics of the Atlantic Niño. To that end, we decompose SST variability into a dynamically driven and a stochastically forced component. Our study is based on experiments that were produced with the Kiel Climate Model, a CGCM: the STD experiment is heavily biased in the equatorial Atlantic, the FLX experiment reduces the bias by applying surface heat flux correction. To decompose total SST variance, we model dynamical SST with empirical linear models that use two predictors, SSH and u10. The choice of our predictors is motivated by the Bjerknes feedback that provides a robust dynamical framework for our purpose. However, the simple concept of the Bjerknes feedback is not always appropriate, and we were careful to note that especially the relationship between SST and u10 works in both directions.

In agreement with numerous previous studies on the dynamics of the Atlantic Niño (e.g. Zebiak 1993; Carton et al. 1996; Ding et al. 2010), we find that dynamical SST variance contributes substantially to equatorial Atlantic SST variability in boreal summer (May-July), the peak phase of the Atlantic Niño. This is in contrast to a recent study by Nnamchi et al. (2015), who found that the Atlantic Niño is driven primarily by stochastic forcing.

Here, we highlight again that a biased background state affects the physics of the tropical Atlantic and can inhibit realistic dynamical behaviour. Our biased experiment fails to simulate a dynamical component of SST variability in boreal summer. The reason is that the biased experiment cannot produce the seasonal cold tongue in the tropical Atlantic. The Atlantic Niño, however, can be understood as a modulation of the cold tongue (Burls et al. 2012). In the absence of the cold tongue, the Atlantic Bjerknes feedback cannot work properly. The biased mean state is not compatible with the dynamic Atlantic Niño that we find in observations.

Taking into account a number of previous studies that found non-negligible lagged relationships in the tropical Atlantic that are related to the Bjerknes feedback, we assess the degree of lag in the Bjerknes feedback elements both in observations and our KCM experiments. In the observations, the Bjerknes feedback is active in the tropical Atlantic in April-May until July and again in November and December. The equatorial bias severely impacts the KCM's ability to simulate a realistic Bjerknes feedback. Additionally, we find that the Atlantic Bjerknes feedback is near-instantaneous during the dynamically active phases of the year. As a consequence, incorporating realistic lagged relationships into our empirical models of dynamical SST hardly impacts the resulting dynamical SST variances. Especially during the important peak phase of the Atlantic Niño both the instantaneous and the lagged empirical models produce identical results.

One consequence of this finding is that we expect potential predictability ${ }^{5}$ of seasonal SST variability to be rather low in the tropical Atlantic. Reasons for this are: (1) when we measure the strength of the Bjerknes feedback elements in terms of anomaly correlation coefficients, Atlantic feedbacks are substantially weaker than their Pacific counterparts, implying that dynamical processes in the equatorial Atlantic are less deterministic than in the tropical Pacific. This is true for both the instantaneous and lagged relationships (not shown). (2) The lack of substantial lags in the Atlantic Bjerknes feedback elements suggests that dynamical processes in the equatorial Atlantic happen on much shorter time scales than in the tropical Pacific. These observations-based conclusions are in line with modelling studies that found the equatorial Atlantic on seasonal time scales to be much less predictable than the equatorial Pacific (e.g. Stockdale et al. 2006).

In addition to the strong dynamical contributions to the Atlantic Niño, we identify a secondary peak in observed dynamical SST variance in November-December in observations. This peak could be associated with Okumura and Xie (2006)'s Atlantic Niño II, a secondary Niño-like phenomenon in the tropical Atlantic that is able to organize SST anomaly growth into a Bjerknes feedback. Note that our adjusted models choose $\mathrm{SSH}, \mathrm{u} 10$, and an interaction term between the two predictors to capture dynamical SST in December. While this could hint at the empirical models having difficulties to predict dynamical SST during December, it could also be due to a feedback linking

\footnotetext{
${ }^{5}$ By potential predictability we mean the predictability that is inherent to the physical climate system and hence independent of whether or not a specific CGCM is able to realise it or not.
} 
the three variables to each other, in this case the Bjerknes feedback. Okumura and Xie (2006)'s findings support the second possibility. Note that, in contrast to May and June, the December peak of enhanced dynamical SST variance is captured by both the FLX and STD experiments, indicating that the KCM appears to be able to reproduce the variability associated with Okumura and Xie (2006)'s Atlantic Niño II.

Our study presented a simple method to decompose eastern equatorial SST variability into dynamic and stochastic contributions while taking into account prominent feedbacks in the region. We are aware that our approach requires assumptions about the processes that could be relevant to SST variability and that we introduce a subjective element into our analysis by selecting a pool of possible predictors that our model adjustment algorithm works on. A thing to keep in mind is that we limit the dynamical processes that can possibly contribute to dynamical SST variability in our empirical models. Figure 6b shows that our decomposition approach produces stochastic SST variances that are consistently higher than the stochastic contributions to SST variability that a standard ensemble averaging approach yields. The reason is most likely that the full CGCM incorporates additional dynamical processes that affect SST evolution. In this sense, ensemble averaging is the more straightforward and complete method to estimate dynamical SST variability. The advantage of our method is that it allows for direct comparisons between observations and model simulations.

While we have provided further evidence for a dynamically driven Atlantic Niño, research is not yet clear on what exactly these dynamics are: If the Bjerknes feedback is involved in establishing the seasonal cold tongue, which processes govern the feedback modulation that produces the interannual variability of the Atlantic Niño? Future study will help to further our understanding of the Atlantic Niño and its predictability.

\begin{abstract}
Acknowledgements We are grateful for extensive reviews by two anonymous reviewers that greatly helped to improve the manuscript. We also thank Ingo Richter and Joke Lübbecke for additional helpful discussions. This study has been supported by the German Ministry for Education and Research (BMBF) through MiKlip2, subproject 01LP1517D (ATMOS-MODINI) and SACUS (03G0837A), and by the European Union 7th Framework Programme (FP7 2007-2013) under Grant agreement 603521 PREFACE project. RJG is also grateful for continuing support from GEOMAR. The data used in this study can be obtained from Tina Dippe (tdippe@geomar.de) on request.
\end{abstract}

Open Access This article is distributed under the terms of the Creative Commons Attribution 4.0 International License (http://creativecommons.org/licenses/by/4.0/), which permits unrestricted use, distribution, and reproduction in any medium, provided you give appropriate credit to the original author(s) and the source, provide a link to the Creative Commons license, and indicate if changes were made.

\section{References}

Bjerknes J (1969) Atmospheric teleconnections from the equatorial pacic. Mon Weather Rev 97(3):163-172. doi:10.1175/1520-0493(1969)097<0163:ATFTEP>2.3.CO;2

Burls NJ, Reason CJC, Penven P, Philander SG (2011) Similarities between the tropical Atlantic seasonal cycle and ENSO: an energetics perspective. J Geophys Res Oceans 116(C11):C11010. doi $: 10.1029 / 2011 \mathrm{JC} 007164$

Burls NJ, Reason CJC, Penven P, Philander SG (2012) Energetics of the Tropical Atlantic zonal mode. J Clim 25(21):7442-7466. doi:10.1175/JCLI-D-11-00602.1

Cane MA (1984) Modeling sea level during El Niño. J Phys Oceanogr 14(12):1864-1874. doi:10.1175/1520-0485(1984)014<1864:MSLDEN>2.0.CO;2

Carton JA, Cao X, Giese BS, Da Silva AM (1996) Decadal and interannual SST variability in the tropical. Atlantic Ocean. doi:10.1175/1520-0485(1996)838026<1165:DAISVI > 2.0.CO;2

Chang CY, Carton JA, Grodsky SA, Nigam S (2007) Seasonal climate of the tropical Atlantic sector in the NCAR community climate system model 3: Error structure and probable causes of errors. J Clim 20(6):1053-1070. doi:10.1175/JCLI4047.1

Davey M et al (2002) STOIC: A study of coupled model climatology and variability 844 in tropical ocean regions. Clim Dyn 18(5):403-420. doi:10.1007/845 s00382-001-0188-6

Dee DP et al (2011) The ERA-Interim reanalysis: configuration and performance of the data assimilation system. Q J R Meteorol Soc 137(656):553-597. doi:10.1002/qj.828

Deppenmeier AL, Haarsma RJ, Hazeleger W (2016) The Bjerknes feedback in the tropical Atlantic in CMIP5 models. Clim Dyn 1-17. doi:10.1007/s00382-016-2992-z

Dijkstra H (2006) The ENSO phenomenon: theory and mechanisms. Adv Geosci 6:3

Ding H, Keenlyside NS, Latif M (2010) Equatorial Atlantic interannual variability: role of heat content. J Geophys Res Oceans 115(C9):C09020. doi:10.1029/2010JC006304

Ding H, Greatbatch RJ, Latif M, Park W, Gerdes R (2013) Hindcast of the 1976/77 and 1998/99 climate shifts in the Paciffic. J Clim 26(19):7650-7661. doi:10.1175/JCLI-D-12-00626.1

Ding H, Greatbatch RJ, Latif M, Park W (2015) The impact of sea surface temperature bias on equatorial Atlantic interannual variability in partially coupled model experiments. Geophys Res Lett 42(13):5540-5546. doi:10.1002/2015GL064799

Draper NR, Smith H (1998) Applied regression analysis. 3rd edn. Wiley, Hoboken. doi:10.1002/9781118625590

Frankignoul C, Hasselman K, Hasselmann K (1977) Stochastic climate models, Part II Application to sea-surface temperature anomalies and thermocline variability. Tellus 29(4):289-305. doi:10.1111/j.2153-3490.1977.tb00740.x

Grodsky SA, Carton JA, Nigam S, Okumura YM (2012) Tropical Atlantic biases in CCSM4. J Clim 25(11):3684-3701. doi:10.1175/JCLI-D-11-00315.1

Harlaß J, Latif M, Park W (2015) Improving climate model simulation of tropical Atlantic sea surface temperature: the importance of enhanced vertical atmosphere model resolution. Geophys Res Lett 42(7):2401-2408. doi:10.1002/2015GL063310

Hirst AC, Hastenrath S (1983) Atmosphere-ocean mechanisms of climate anomalies in the Angola-tropical Atlantic sector. J Phys Oceanogr 13(7):1146-1157. doi:10.1175/1520-0485(1983)013<1146:AOMOCA > 2.0.CO;2

$\mathrm{Hu}$ Z-Z, Huang B (2007) The predictive skill and the most predictable pattern in the tropical Atlantic: the effect of ENSO. Mon Weather Rev 135(5):1786-1806. doi:10.1175/MWR3393.1

Janicot S, Harzallah A, Fontaine B, Moron V (1998) West African monsoon dynamics and eastern equatorial Atlantic and 
Pacific SST anomalies (1970-88). J Clim 11(8):1874-1882. doi:10.1175/1520-0442(1998)011<1874:WAMDAE > 2.0.CO;2

Keenlyside NS, Latif M (2007) Understanding equatorial Atlantic Interannual variability. J Clim 20(1):131-142. doi:10.1175/ JCLI3992.1

Kushnir Y, Robinson WA, Chang P, Robertson AW (2006) The physical basis for predicting Atlantic sector seasonal-to-interannual climate variability. J Clim 19(23):5949-5970. doi:10.1175/ JCLI3943.1

Lübbecke JF, McPhaden MJ (2012) On the inconsistent relationship between Pacific and Atlantic Nifngos. J Clim 25(12):4294-4303. doi:10.1175/JCLI-D-11-00553.1

Lübbecke JF, McPhaden MJ (2013) A comparative stability analysis of Atlantic and Paciffic Niño modes. J Clim 26(16):5965-5980. doi: 10.1175/JCLI-D-12-00758.1

Lübbecke JF, McPhaden MJ (2017) Symmetry of the Atlantic Niño mode. Geophys Res Lett 44(2):965-973. doi:10.1002/201 6GL071829

Lübbecke JF Burls NJ, Reason CJC, McPhaden MJ (2014) Variability in the South Atlantic Anticyclone and the Atlantic Nifñgo Mode. J Clim 27(21):8135-8150. doi:10.1175/JCLI-D-14-00202.1

Madec G, Delecluse P, Imbard M, Levy C (1998) OPA 8.1 general circulation model reference manual. Tech. rep. Paris: Institut Pierre-Simon Laplace

Madec G (2008) NEMO ocean general circulation model reference mannuel. Tech. rep. Paris: Institut Pierre-Simon Laplace

Marin F, Caniaux G, Giordani H, Bourlès B, Gouriou Y, Erica K (2009) Why were sea surface temperatures so different in the eastern equatorial Atlantic in June 2005 and 2006? J Phys Oceanogr 39(6):1416-1431. doi:10.1175/2008JPO4030.1

Mohino E, Losada T (2015) Impacts of the Atlantic equatorial mode in a warmer climate. Clim Dyn 45(7-8):2255-2271. doi:10.1007/ s00382-015-2471-y (English)

Neelin JD, Battisti DS, Hirst AC, Jin F-F, Wakata Y, Yamagata T, Zebiak SE (1998) ENSO theory. J Geophys Res 103(C7):14261. doi:10.1029/97JC03424

Nnamchi HC, Li J, Kucharski F, Kang IS, Keenlyside NS, Chang P, Farneti R (2015) Thermodynamic controls of the Atlantic Niño. Nat Commun 6:8895. doi:10.1038/ncomms9895

Nnamchi HC, Li J, Kucharski F, Kang I-S, Keenlyside NS, Chang P, Farneti R (2016) An equatorial-extratropical dipole structure of the Atlantic Niño. J Clim 29(20):7295-7311. doi:10.1175/ JCLI-D-15-0894.1

Okumura Y, Xie SP (2006) Some overlooked features of tropical Atlantic climate leading to a new Nino-like phenomenon. J Clim 19(22):5859-5874

Park W, Keenlyside N, Latif M, Ströh A, Redler R, Roeckner E, Madec G (2009) Tropical Paciffic climate and its response to globalwarming in the Kiel climate model. J Clim 22(1):71-92. doi:10.1175 /2008JCLI2261.1
Rayner NA, Parker D, Horton E, Folland C, Alexander L, Rowell D, Kent E, Kaplan A (2003) Global analyses of sea surface temperature, sea ice, and night marine air temperature since the late nineteenth century. J Geophys Res 108(D14):4407. doi:10.1029 /2002JD002670

Richter I, Xie S-P (2008) On the origin of equatorial Atlantic biases in coupled general circulation models. Clim Dyn 31(5):587-598. doi:10.1007/s00382-008-0364-z (English)

Richter I, Xie SP, Wittenberg AT, Masumoto Y (2012) Tropical Atlantic biases and their relation to surface wind stress and terrestrial precipitation. Clim Dyn 38(5-6):985-1001. doi:10.1007/ s00382-011-1038-9

Richter I, Behera SK, Masumoto Y, Taguchi B, Sasaki H, Yamagata $\mathrm{T}$ (2013) Multiple causes of interannual sea surface temperature variability in the equatorial Atlantic Ocean. Nat Geosci 6(1):4347. doi:10.1038/ngeo1660

Richter I, Xie SP, Behera SK, Doi T, Masumoto Y (2014a) Equatorial Atlantic variability and its relation to mean state biases in CMIP5. Clim Dyn 42(1-2):171-188. doi:10.1007/s00382-012-1624-5

Richter I, Behera SK, Doi T, Taguchi B, Masumoto Y, Xie SP (2014b) What controls equatorial Atlantic winds in boreal spring? Clim Dyn 43(11):3091-3104. doi:10.1007/s00382-014-2170-0

Richter I, Xie SP, Morioka Y, Doi T, Taguchi B, Behera S (2016) Phase locking of equatorial Atlantic variability through the seasonal migration of the ITCZ. Clim Dyn 1-15. doi:10.1007/ s00382-016-3289-y

Roeckner E, Bäuml G, Bonaventura L, Brokopf R, Esch M, Giorgetta M, Hagemann S, Kirchner I, Kornblueh L, Rhodin A, Schlese U, Schulzweida U, Tompkins A (2003) The atmospheric general circulation model ECHAM5: Part 1: Model description. MPI Rep 349:1-140. doi:10.1029/2010JD014036

Stockdale TN, Balmaseda MA, Vidard A (2006) Tropical Atlantic SST prediction with coupled Ocean-Atmosphere GCMs. J Clim 19(23):6047-6061. doi:10.1175/JCLI3947.1

Thoma M, Greatbatch RJ, Kadow C, Gerdes R (2015) Decadal hindcasts initialized using observed surface wind stress: evaluation and prediction out to 2024. Geophys Res Lett. doi:10.1002/201 5GL064833

Wang C, Zhang L, Lee S, Wu L, Mechoso CR (2014) A global perspective on CMIP5 climate model biases. Nat Clim Change 4:201205. doi:10.1038/NCLIMATE2118

Xie SP, Carton JA (2004) Tropical Atlantic variability: patterns, mechanisms, and impacts. Earth's Clim. American Geophysical Union 121-142. doi:10.1029/147GM07

Zebiak SE (1993) Air-sea interaction in the equatorial Atlantic region. J Clim 6(8):1567-1586. doi:10.1175/1520-0442(1993)006<1567:AIITEA > 2.0.CO;2

Zhu J, Huang B, Wu Z (2012) The role of ocean dynamics in the interaction between the Atlantic meridional and equatorial modes. $\mathrm{J}$ Clim 25(10):3583-3598. doi:10.1175/JCLI-D-11-00364.1 